\title{
AUDITORY BRAINSTEM RESPONSES: STIMULUS VARIATIONS
}

\author{
Ana Claudia Bianco Gução' ${ }^{1}$ Ana Carla Leite Romero², Franciny Luque Lemes ${ }^{3}$, \\ Simone Fiuza Regaçone ${ }^{4}$, Vitor Engracia Valenti ${ }^{5}$, Ana Cláudia Figueiredo Frizzo ${ }^{6}$
}

\begin{abstract}
Introduction: Auditory brainstem response is a response to external stimulation that represents the neural electrophysiological activity of the auditory system at the brainstem level. Variations due to the change in the presentation of stimuli help in the diagnosis of clinical conditions that affect the auditory nervous system. Objective: To characterize and compare the different polarity variations stimuli and presentation rates in adults with normal hearing. Methods: We investigated 20 students from a Center for Diagnosis and Rehabilitation, with no hearing impairment, all female aged 15-30 years old, who were screened for brainstem auditory evoked potential, which presented stimuli in different polarities ranges, including condensation and rarefaction in different presentation rates of 21.7, 27.7 and 47.7 stimuli per second. Results: We observed lower values of latencies of wave I in the three rates of stimulus presentation and wave $V$ at the rate of $21.7 / \mathrm{sec}$. rarefact when used, and also on the right ear and the same polarity, the gap interpeak I - III also had lower values for rates of introduction, as in the IR range the rate of $21.7 / \mathrm{s}$. In overall comparison of groups in different polarities of stimulation, there was a significant difference only in rarefact. Conclusion: The understanding of the behavior of the electrophysiological response to variations of the stimulus is important and may serve as a reference for normal use of these measures in clinical practice.
\end{abstract}

DOI: http://dx.doi.org/10.7322/jhgd.106001

Keywords: auditory evoked potentials, hearing, normal values, brain stem.

\section{INTRODUCTION}

The Brainstem Auditory Evoked Response (BAEP) is a complex response to externalstimulation that represents the neural electrophysiological activity of the auditory system at the level of the brainstem, mapping the synapses of the auditory pathways from the cochlear nerve, cochlear nucleus, superior olivary brainstem complex to the inferior colliculus-midbrain ${ }^{1,2}$.

Featured by a series of seven waves, which can be recorded by forehead or brow - lobe mastoid derivation electrodes during the first 12 milliseconds(ms) after moderate sound stimulus. These waves sequentially labeled with Roman/ numerals appear to represent successive tracts and/ or auditory pathway synapses. These seven waves, the top five most interest and, among them, the waves I, III and $V$ are those that offer the most important parameters for interpretation of BAEP ${ }^{2,3}$.

Wave I is generated in the distal portion of the brainstem to the auditory nerve, wave II is generated in the proximal portion of the brainstem to the auditory nerve ${ }^{4,5}$. Waves I and II are generated in the cochlear nerve and subsequent have multiple generators, although there is no precise definition of the contribution of the structures for the appearance of each power. However, studies have shown that wave III is generated in neurons that emerge from the cochlear nucleus complex ${ }^{2}$, the wave IV by the superior olivary complex and peak which represents the wave $\mathrm{V}$ is generated by the contralateral inferior colliculus cells $^{6}$. The wave VI is generated in the inferior colliculus and the wave VII in the medial geniculate nucleus ${ }^{(4,5)}$. It should be emphasized that the peaks of the waves IV, V, VI and VII of the BAEP have complex origin, with more than one anatomical structure contributing to the formation of each peak. The only binding sites of synapse in the auditory pathways of the brainstem are the inferior colliculus and the cochlear nucleus and between these pathways exists a series of parallel pathways ${ }^{7}$.

To perform the test it used an electronic device comprising a acoustic signal computer mediator generator, amplifier and recorder. Responses occur after a sound stimulus, presented through headphones or bone vibrators 8,9 . In addition, in the computer some characteristics that define certain acquisition parameters record the

\footnotetext{
1 Speech-Language Therapist. Master in Communication Disorders. Faculty of Sciences, University Estadual Paulista - FFC/UNESP Marilia - SP / Brazil.

2 Speech-Language Therapist. Master in Communication Disorders. Faculty of Sciences, University Estadual Paulista - FFC/UNESP Marilia - SP/Brazil.

3 Speech-Language and Hearing Therapist. 3 Speech-Language Therapist. Faculty of Sciences, University Estadual Paulista - FFC/ UNESP Marilia - SP/Brazil.

4 Speech-Language Therapist. Faculty of Sciences, University Estadual Paulista - FFC/UNESP Marilia - SP/Brazil.

5 Physiotherapist. Assistant Professor, Department of Speech-Language Therapy, Faculty of Sciences, University Estadual Paulista FFC - UNESP - Marilia (SP), Brazil.

6 Speech-Language Therapist. Assistant Professor, Department of Speech-Language Therapy, Faculty of Sciences, University Estadual Paulista - FFC - UNESP - Marilia (SP), Brazil.

Corresponding author: Vitor Engrácia Valenti. Email: vitor.valenti@gmail.com
} 
type, intensity and polarity of stimulation. The BAEP are considered exogenous potentials, ie, the characteristics of the stimulus used directly influence the response. Among these characteristics we can mention the type of stimulus intensity, rate of presentation and polarity ${ }^{10,11}$.

Regarding the polarity of the stimuli we may mention three types: rarefaction (negative polarity), condensation (positive polarity) and alternating (polarity negative/positive). The way in which the auditory system responds to stimuli differs according to type, rarefaction is observed usually during outward movement of the stapes and during upward movement in the structures of the organ of Corti. In the condensation, the initial movement of the stapes occurs inside, followed by an inverse movement to that described above. During alternating polarity there is a combination between the polarities of condensation and rarefaction in subsequent presentations ${ }^{(11,12)}$. The rarefaction and condensation differ as to the direction that the initial movement of the diaphragm of the headset is on the tympanic membrane (12).

Previous studies presented evidence that the sensitivity of BAEP to auditory disorders may vary according to the polarity of the click used, in addition to significantly influence the absolute latencies and interpeak latencies of waves I, III and $\mathrm{V}^{10,11}$.

The main purpose of the use of alternate click on the BAEP is the cancellation of the electrical artifact at the beginning of the record of the response generated by the receiver surface, TDH 39, for instance, making difficult to observe Wave I. Currently, with the use of insert earphones, the simple polarity, rarefaction or condensation becomes more appropriate, especially when the primary purpose of the examination is to determine the latency of wave $\mathrm{V}$, since the negative polarity (rarefaction) allows its registration with greater clarity and separation in many cases of the complex IV-V².

Another point of interest in scientific research involving variation of the stimulus is the variation of the rate of presentation that has also been attributed to the differential diagnosis. Faster rates of stimulus presentation cause less reproduction and clarity of the waves than in slower rates of presentation, showing increased amplitude of the waves and significant improvement in their standard ${ }^{13}$.

The same is reported by other authors ${ }^{14}$ who also observed lower reproducibility of the waves with the highest rate of presentation, but it was cited that a faster rate makes testing faster.

It is expected that this study provides additional knowledge regarding the variations due to the change in polarity parameters and rate of presentation. Therefore, it can contribute to standardize clinical practice and to improve clinical diagnostic conditions that affect the auditory nervous system.

The aim of this study is to characterize and compare the different polarity variations stimuli and presentation rates in adults with normal hearing.

\section{METHODS}

This is a cross-sectional study that was approved by the Ethics Committee in Research of the Faculty of Philosophy and Sciences - CEP/FFC/ UNESP, case number $0210 / 2011$.
This study was conducted at the Faculty of Philosophy and Sciences - Marília Campus Center for the Study of Education and Health (CEES), Paulista State University "Júlio de Mesquita Filho".

The sample size was estimated by calculating the sample size for medium infinite population (insert quote. Thus, alpha $=0.05$, beta equal to 0.1 , standard deviation of 0.2 (ms) and tolerable error 0.5 (ms) corresponding to two standard deviations of the sample. Then, the sample size was set at 20 .

The study included 22 female subjects, aged 15-30 years old, among them it was included students and trainees of this study center, which did not present hearing loss, audiometric thresholds up to $25 \mathrm{~dB} \mathrm{HL}$. Two participants in the study had abnormal tympanometry measure. Both were referred to the otolaryngologist and were excluded in the study.

We considered as inclusion criteria subjects with no neurological, mental and motor damage and auditory impairment verified through audiological tonal examination with thresholds below $25 \mathrm{dBHL}$, according to Lloyd and Kaplan ${ }^{16}$ and tympanometry presenting type curve, indicating normal mobility of the tympanic - ossicular system according Jerger ${ }^{17}$.

As resolution of the National Health Council $196 / 96$ prior to the beginning of the tests, the participants signed an Informed Consent letter to permit the completion of the study.

It was initially performed the inspection of the external auditory canal through otoscope, checking the conditions for carrying out the audiometry and electrophysiological tests. Pure tone audiometry was performed with pure tones in a soundproof booth, and evaluated the frequencies from 250 to $8000 \mathrm{~Hz}$ by air, being considered normal according to the hearing threshold of $25 \mathrm{dBHL}$. We used the two-channel audiometer GSI 61 middle ear analyzer and GSI - 7 in order to verify if the individual meets the hearing conditions within normal limits and does not present middle ear disorders.

The electrophysiological assessment of the BAEP we used the Biologic Navigator Pro and electrodes placed on the forehead ( $F z$ and $F p z$ ) in reference to the right and left ears( $A 1$ and $A 2)$. The electrodes were fixed with microporous tape after cleaning the skin with BAEPasive paste, electrolytic paste was used to improve the electrical conductivity. The impedance of each electrode did not exceed 5 kohms and 2 kohms between the impedances eletrodes ${ }^{12}$. The stimulus used was the monaural condensed and rarefied click at $80 \mathrm{dBNAn}$. Presentation rates used were $21.7 / \mathrm{sec} ., 27.7 / \mathrm{sec}$. and $47.7 / \mathrm{sec}$., to assess the integrity of the auditory pathway and to compare the absolute latencies of waves I, III and V and interpeak I-III, III-V and IV. Groups were formed with the values of the BAEP as differing rates of presentation and polarities for comparisons.

Subjects were accommodated in a recliner and asked to remain relaxed with eyes closed or even sleep state for the acquisition of Auditory brainstem. The exam environment was electrical and sound proof.

We performed descriptive statistics(mean and standard deviation), and absolute latency and 
interpeak frequency of 80 dBNA in the different stimuli .

The normality of the data was determined by the Shapiro - Wilk test. To compare the results of the values of absolute and interpeak latencies of the different rates of presentation and their different polarities of stimulation, we used the paired Student $t$ test and Wilcoxon test. For the comparison of absolute latencies and interpeak intervals at different polarities between stimulus and rate of presentation, we used the Kruskal Wallis test followed by Bonferroni and one way ANOVA followed by Dun. Significant difference was considered for $p<0,05$.

\section{RESULTS}

Tables 1 and 2 show the mean and standard deviation (SD) of the absolute latencies and interpeak found in different polarities of the click stimulus(rarefaction and condensation) and different presentation rates(21.7, 27.7 and 477$)$.

Table 1: Descriptive statistical analysis of the BAEP, and absolute latency in frequency $80 d B N A$ as to the rate of stimulation in different stimuli $(n=20)$

\begin{tabular}{|c|c|c|c|c|c|c|c|c|c|c|}
\hline \multicolumn{11}{|c|}{ Brainstem Audi } \\
\hline & Waves & I & I & I & III & III & III & V & V & V \\
\hline & Stimuli & 21,7 & 27,7 & 47,7 & 21,7 & 27,7 & 47,7 & 21,7 & 27,7 & 47,7 \\
\hline RE & $\begin{array}{l}\text { SD } \\
\text { Mean }\end{array}$ & 1,53 & 1,54 & 1,56 & 3,53 & 3,55 & 3,58 & 5,28 & 5,32 & 5,41 \\
\hline & SD & 0,1 & 0,13 & 0,09 & 0,1 & 0,1 & 0,08 & 0,16 & 0,16 & 0,17 \\
\hline LE & Mean & 1,6 & 1,59 & 1,64 & 3,58 & 3,59 & 3,63 & 5,37 & 5,4 & 5,47 \\
\hline Condensed & SD & 0,13 & 0,13 & 0,13 & 0,13 & 0,14 & 0,12 & 0,18 & 0,18 & 0,15 \\
\hline & Mean & 1,57 & 1,6 & 1,62 & 3,53 & 3,54 & 3,59 & 5,33 & 5,34 & 5,42 \\
\hline RE & $\begin{array}{l}\text { SD } \\
\text { Mean }\end{array}$ & $\begin{array}{l}0,1 \\
1,6\end{array}$ & $\begin{array}{l}0,11 \\
1,62\end{array}$ & $\begin{array}{l}0,09 \\
1,67\end{array}$ & $\begin{array}{l}0,12 \\
3,56\end{array}$ & $\begin{array}{l}0,12 \\
3,6\end{array}$ & $\begin{array}{l}0,11 \\
3,64\end{array}$ & $\begin{array}{l}0,14 \\
5,36\end{array}$ & $\begin{array}{l}0,13 \\
5,37\end{array}$ & $\begin{array}{l}0,13 \\
5,48\end{array}$ \\
\hline LE & SD & 0,14 & 0,13 & 0,13 & 0,17 & 0,15 & 0,14 & 0,18 & 0,2 & 0,17 \\
\hline
\end{tabular}

Caption 1: RE: right ear, LE: left ear; + SD: Standard Deviation.

Table 2: Descriptive statistical analysis of the BAEP, as the intervals range from $80 \mathrm{dBNA}$ in the frequency range of polarity regarding the different stimuli $(n=20)$

\begin{tabular}{|c|c|c|c|c|c|c|c|c|c|c|}
\hline \multirow{2}{*}{ Rarefied } & \multicolumn{8}{|c|}{$\begin{array}{c}\text { Brainstem Auditory Evoked Response } \\
\text { Interpeak intervals (ms) }\end{array}$} & \multirow[b]{2}{*}{$\mathrm{I}-\mathrm{V}$} & \multirow[b]{2}{*}{ I-V } \\
\hline & Waves & I-III & I-III & I-III & III-V & III-V & III-V & $\mathrm{I}-\mathrm{V}$ & & \\
\hline \multirow{3}{*}{ RE } & Stimuli & 21,7 & 27,7 & 47,7 & 21,7 & 27,7 & 47,7 & 21,7 & 27,7 & 47,7 \\
\hline & Mean & 2,00 & 2,00 & 2,01 & 1,74 & 1,77 & 1,83 & 3,75 & 3,77 & 3,84 \\
\hline & SD & 0,05 & 0,08 & 0,06 & 0,11 & 0,13 & 0,15 & 0,12 & 0,15 & 0,15 \\
\hline \multirow[t]{2}{*}{ LE } & Mean & 1,95 & 2,00 & 1,99 & 1,87 & 1,81 & 1,83 & 3,84 & 3,81 & 3,82 \\
\hline & SD & 0,14 & 0,05 & 0,09 & 0,42 & 0,10 & 0,10 & 0,40 & 0,11 & 0,11 \\
\hline \multicolumn{11}{|l|}{ Condensed } \\
\hline \multirow[t]{2}{*}{$\mathrm{RE}$} & Mean & 1,95 & 1,93 & 1,97 & 1,80 & 1,80 & 1,83 & 3,76 & 3,74 & 3,80 \\
\hline & SD & 0,07 & 0,10 & 0,06 & 0,09 & 0,08 & 0,07 & 0,00 & 0,11 & 0,09 \\
\hline \multirow[t]{2}{*}{ LE } & Mean & 1,95 & 1,98 & 1,97 & 1,80 & 1,77 & 1,84 & 3,76 & 3,75 & 3,81 \\
\hline & SD & 0,09 & 0,07 & 0,06 & 0,15 & 0,14 & 0,08 & 0,17 & 0,16 & 0,07 \\
\hline
\end{tabular}

Caption 2: RE: right ear, LE: left ear; † SD: Standard Deviation.

With the results obtained by statistical analysis it was possible to notice a slight difference in the values of latencies and intervals on the effect that changing polarity and presentation rate on latency and interlatency waves, appearing in both the mean and standard deviation values of some smaller or equal in rarefact.

Tables 3 and 4 show the average of the different stimulus polarities of waves I, III and V and interpeak intervals, respectively, comparing their different variations of presentation of right and left ears. The values calculated using the statistical Student t tests and Wilcoxon tests indicated that there was a statistically significant difference in the right ear for the latency of wave I at all rates of presentation and wave $\mathrm{V}$ only on presentation rate of $21.7 / \mathrm{sec}$. In the analysis of interpeak I-III there was also no statistically significant difference in all rates of presentation, and the I- $\mathrm{V}$ interval in the presentation rate of $21.7 / \mathrm{sec}$. in the right ear, and there was no significant difference in the left ear in both tables.

The Kruskal Wallis and one way ANOVA statistical tests followed by Dun and Bonferroni, respectively, were used to compare the average of all rates of presentation at different polarities of stimulation, which is found in Table 5, showing significant difference in mean latencies obtained among all rates of presentation in waves I and III of the right and left ears and III - V interpeak interval of the right ear, when analyzing the rarefact. In the analysis of condensed polarity there was no significant differences in both ears.

\section{DISCUSSION}

It is of utmost importance for the diagnosis and to obtain a topographic diagnosis of hearing 
Table 3: Comparison of different rates of presentation of waves I, III and V, the average of the different polarities of stimulation $(n=20)$

\begin{tabular}{|c|c|c|c|c|c|c|c|c|c|c|}
\hline & & & & Brainst & $\begin{array}{l}\text { Auditc } \\
\text { olute }\end{array}$ & $\begin{array}{l}\text { Evoked } \\
\text { ncy (m }\end{array}$ & spons & & & \\
\hline Con & parison & arefied & ondense & & & & & & & \\
\hline & Waves & I & I & I & III & III & III & V & V & V \\
\hline & Stimuli & 21,7 & 27,7 & 47,7 & 21,7 & 27,7 & 47,7 & 21,7 & 27,7 & 47,7 \\
\hline RE & p-value & $0,039 *$ & $0,007 *$ & $0,004 *$ & 0,672 & 0,641 & 0,462 & $0,010 *$ & 0,328 & 0,589 \\
\hline LE & p-value & 0,864 & 0,513 & 0,709 & 0,580 & 0,933 & 0,949 & 0,729 & 0,292 & 0,592 \\
\hline
\end{tabular}

Legend 3: RE: right ear, LE: left ear, ms: milliseconds. Student's t test $* /$ a Wilcoxon test $(p<0.05)$.

\begin{tabular}{|c|c|c|c|c|c|c|c|c|c|c|}
\hline \multicolumn{11}{|c|}{$\begin{array}{c}\text { Brainstem Auditory Evoked Response } \\
\text { Interpeak intervals ( } \mathrm{ms})\end{array}$} \\
\hline \multicolumn{11}{|c|}{ Comparison rarefied $\mathbf{x}$ condensed } \\
\hline & Waves & I-III & I-III & I-III & III-V & III-V & III-V & I-V & I-V & I-V \\
\hline & Stimuli & 21,7 & 27,7 & 47,7 & 21,7 & 27,7 & 47,7 & 21,7 & 27,7 & 47,7 \\
\hline RE & p-value & $0,039 *$ & $0,007 *$ & $0,004 *$ & 0,672 & 0,641 & 0,462 & $0,010 *$ & 0,328 & 0,589 \\
\hline LE & p-value & 0,850 & 0,191 & 0,310 & 0,962 & 0,234 & 0,889 & 0,930 & 0,134 & 0,563 \\
\hline
\end{tabular}

Legend 4: RE: right ear, LE: left ear, ms: milliseconds. Student's t test * / a Wilcoxon test $(p<0.05)$.

Table 5: Comparison of absolute latencies ( $\mathrm{ms}$ ) and interpeak intervals obtained in the click stimulus polarity ( rarefied and condensed ) taking the average of all presentation rates used ( $21.7,27.7$ and $47.7 /$ sec. $)(N=20)$

\begin{tabular}{|c|c|c|c|c|c|c|c|}
\hline \multirow{3}{*}{ Rarefied } & \multirow{3}{*}{ Waves } & \multicolumn{6}{|c|}{ Brainstem Auditory Evoked Response } \\
\hline & & \multicolumn{3}{|c|}{ Absolute latency (ms) } & \multicolumn{3}{|c|}{ Interpeak intervals } \\
\hline & & I & III & V & I-III & III-V & I-V \\
\hline RE & & $0,0071 *$ & $0,0023 *$ & 0,0542 & 0,9340 & $0,0006 *$ & 0,1509 \\
\hline LE & & $0,0169 *$ & $0,0009 *$ & 0,1886 & 0,7538 & 0,3252 & 0,2800 \\
\hline \multicolumn{8}{|c|}{ Condensed } \\
\hline RE & & 0,2999 & 0,2122 & 0,0933 & 0,0876 & 0,5451 & 0,1660 \\
\hline LE & & 0,2838 & 0,3032 & 0,1029 & 0,7827 & 0,1745 & 0,5341 \\
\hline
\end{tabular}

Legend 5: RE right ear, LE: left ear, ms: milliseconds. Kruskal-Wallis ANOVA and followed by Dun $(p<0.05)$

disorders the interaural comparison of the values of the absolute latencies of waves I, III and V and I- III, IV and III - V interpeak intervals².

The different variations in the characteristics of the BAEP stimuli assist in evaluation of the different auditory pathologies, individually adjusting the polarity and rate of stimulus presentation according to the needs.

The average values of absolute latencies and interpeak latencies of waves I, III and V are lower in general regarding the rarefaction polarity compared to the polarities of condensation ${ }^{11}$. This was also observed in the present study, we found small difference in the values of I and $\mathrm{V}$ latencies and I-III and IV interpeak intervals between different polarities, obtaining mostly smaller rarefact values. Other studies ${ }^{10,18,19}$ have also shown that there are differences between the two variations of stimulus, indicating lower latency in the rarefaction polarity compared to condensation.

Changes in stimulus polarity assist in the evaluation of individuals with hearing impairments, as in auditory neuropathy and this change is crucial for obtaining presence of cochlear microphonic increased and may be a reflection of the dysfunction of outer hair cells of these individuals ${ }^{20}$.

In order to analyze the effect of changes in stimulus characteristics, a previous study ${ }^{21}$ evaluated 59 patients with hearing impairment during the BAEP, reversing the rarefied and condensed polarities in presentation rate of $27.7 /$ sec. They observed differences in tracing waves when alternating the polarity of the stimulus, concluding that these differences help the topographic diagnosis of deafness.

It is shown from the analysis of absolute latencies of waves and interlatencies that the higher the rate of stimulus presentation, the smaller its reproducibility. This is also described in other studies $^{14,22}$, however, it was mentioned the positive aspects of using a higher rate of presentation, justifying by making the procedure faster, a fact confirmed in this study, and to be able to detect unregistered changes when using lower speeds stimulus.

In the case of individuals diagnosed with auditory neuropathy, the faster rate of stimulus presentation, even being useful by less time spent in the exam, lower reproduction and clarity of the waves $^{13}$, because, it requires greater activity of the auditory nerve, which is affected in these patients.

Based on the facts mentioned above, it is recommended the patients to be tested at least in two stimulus presentation rates, low and high, in order to sensitize the BAEP in detecting retrocochlear disorders ${ }^{23}$.

This study shows that the variation of the polarity of the stimulus is of great importance to clinical findings, we reported significant differences when used in rarefact while there was no significant difference when performed in condensed polarity. The variation of the rate of presentation is important to assist in the analysis of different latencies responses and interlatencies waves, showing significant differences between them, being primarily evidenced in wave I at all rates used. 
These variations in polarity and stimulus rate on BAEP are important to assist in the detection of pathologies and hearing and understanding the behavior of the electrophysiological response to variations of the stimulus is important and serves as a reference for normal use of these measures in clinical practice.

However the current shortage literature on this topic, limited the opposition or agreement of the findings of this study with those of other authors.

\section{REFERENCES}

1. Sleifer P, Costa SS, Cóser PL, Goldani MZ, Dornelles C, Weiss K. Auditory brainstem response in premature and full-term children. Int J PediatrOtorhinolaryngol. 2007;71: 1449-56. DOI: http://dx.doi.org/10.1016/j.ijporl.2007.05.029

2. Sousa LCA, Piza MRT, Alvarenga KF, Cóser PL. Evoked Auditory Brainstem Response (BAEP). Electrophysiology of Hearing and otoacoustic emissions: principles and clinical applications. São Paulo: Tecmedd; 2008; p. $49-87$

3. Sousa LCA, LS Rodrigues, Piza MRT, Ferreira DR, Ruiz DB. Occasional finding of neurological research for childhood hearing loss using the ABR. Rev Bras Otorrinolaringol. 2007; 73(3): 424-28. DOI: http:/ /dx.doi.org/10.1590/S0034-72992007000300020

4. Pinto FR, Woods CG. Comparison between auditory thresholds and electrophysiological tone bursts. RevBrasOtorrinolaringol. 2007;73(4):513-22. DOI: http://dx.doi.org/10.1590/S0034-72992007000 400010

5. Esteves MCBN, Del'Aringa AHB, Arruda GV, Aringa ARD, Nardi JC. Brainstem evoked response audiometry in normal hearing subjects. Braz J Otorhinolaryngol. 2009;75(3):420-5. DOI: http:// dx.doi.org/10.1590/S1808-86942009000300018

6. Moller A. Neural generators for auditory brainstem evoked Potentials. In: Kard RF, Don M, Eggermont JJ. Auditory Evoked Potentials. Basic principles and clinical application. Baltimore Lippincott Williams \& Wilkins; 2007; p.336-354.

7. Antoneli MZ, Zanchetta S, Zorzetto NL, Ribeiro LA, Richieri-Costa A. Holoprosencephaly: clinical evaluation on audiological and brainstem electrophysiological profiles. Am J Med Genetics. 2006; 140A(19):2142-2145. DOI: http://dx.doi.org/ 10.1002/ajmg.a

8. Matas CG, Leite A, Gonçalves IC, IF Neves. Brainstem Evoked Potentials with Conductive and Sensorineural Hearing Loss. Arq Inter Otorrinolaringol. 2005;9(4).

9. Soares IA, PL Menezes, Carnauba ATL, Pereira LD. Standardization of brainstem auditory evoked potential using a new device. Pro-FonoRev Atual Cient. 2010; 22(4):421-6. DOI: http://dx.doi.org/ 10.1590/S0104-56872010000400010

10. Fowler CG, Bauch CD, Olsen WO. Diagnostic implications of stimulus polarity effects on the

\section{CONCLUSION}

The change in polarity and stimulus presentation rate on examination of influences BAEP responses, mainly rarefaction polarity. Therefore, it is suggested that further research with a larger number of individuals on both genders with normal hearing to confirm that these findings and to contribute to the standardization of clinical practice.

auditory brainstem response. J AmAcadAudiol. 2002; 13(2): $72-82$

11. Lima JP, Alvarenga KF, Foelkel TP, Monteiro CZ, Agostinho RS. Polarity stimulation effects on brainstem auditory evoked potentials. Rev Bras Otorrinolaringol. 2008;74(5):725-730.

12. Hall JW. New Handbook of Auditory Evoked Responses. Boston: Allyn \& Bacon; 2006.

13. Hood LJ. Clinical applications of the auditory brainstem response. San Diego: Singular Publishing Group;1998; p.12-28 .

14. Burkard RF, Sims D. The Human Auditory Brainstem Response to high click rates: Aging effects. Am J Audiol. 2001;10(2):53-61.

15. Vieira S. Introdução à bioestatística. Elsevier Brasil; 2011.

16. Lloyd LL, Kaplan H. Audiometric interpretation: a manual the basic audiometry. Baltimore: University Park Press; 1978; p.16-7.

17. Jerger J. Clinical experience with impedance audiometry. Arch Otolaryngol. 1970;92 (4):311-24 . DOI: http://dx.doi.org/10.1001/archotol.1970. 04310040005002

18. Rawool VW. Effects of click polarity on the auditory brainstem responses of older men. Audiology. 1998;37(2):100-8

19. Ferraro JA, Durrant JD. Auditory Evoked Potentials: general vision and principles. In: Katz J. Treaty of Clinical Audiology. 4th. Manole; 1999; p.315-336.

20. Starr A. The neurology of auditory neuropathy. In: Sininger IA. Starr Auditory neuropathy, a new perspective on hearing disorders. San Diego: Singular Publishing Group; 2001; p.37-49.

21. Fávero ML, Silva FLC, Tabith Junior A, Nicastro FS, Gudmond MC, Spinelli M. Changes in click characteristics during ABR recording. Rev Bras Otorrinolaringol. 2007;73(1):7-11. DOI: http:// dx.doi.org/10.1590/S0034-72992007000100002

22. Stürzebecher E, Cebulla M, Neumann K. Click-evoked BAEP at high stimulus repetition rate for neonatal hearing screening. Int J Audiol. 2003;42(2):59-70.

23. Tanaka $H$, Komatsuzaki A, Hentona $H$. Usefulness of auditory brainstem responses at high stimulus rates in the diagnosis of acoustic neuroma. ORL J OtorhinolaryngolRelat Spec. 1996; 58(4): 224-8. DOI: http://dx.doi.org/10.1159/000276841

\section{Resumo}

Introdução: potencial evocado auditivo é uma resposta a um estímulo externo que representa a atividade eletrofisiológica do sistema auditivo em nível do tronco cerebral. Variações devido à alteração na apresentação de estímulos ajudam no diagnóstico de condições clínicas que afetam o sistema nervoso auditivo. Objetivo: Caracterizar e comparar as diferentes variações de polaridade de estímulos e as taxas de apresentação em adultos com audição normal. Método: foram investigados 20 estudantes de um centro de diagnóstico e de reabilitação, sem deficiência auditiva, todos do sexo feminino com idade de 15-30 anos de idade, que foram selecionados para potencial evocado auditivo de tronco cerebral, que apresentou estímulos em diferentes polaridades varia, incluindo a condensação e rarefação em diferentes taxas de apresentação de 21,7, 27,7 e 47,7 estímulos por segundo. Resultados: foram observados menores valores de latências da onda I nas três taxas de apresentação do estímulo e da onda $\mathrm{V}$ a uma taxa de 21,7 / seg. Em polaridade rarefeita, quando utilizado, e também sobre a orelha direita e a mesma polaridade, o fosso intérpico I - III tinha também apresentou valores mais baixos para as taxas, como na gama de IV a taxa de $21,7 / \mathrm{s}$. Na comparação geral dos grupos em diferentes polaridades de estimulação houve diferença significativa apenas na polaridade rarefeita. Conclusão: a compreensão do comportamento de resposta a variações eletrofisiológicas de estímulo é importante e pode servir como uma referência para o uso destas medidas na prática clínica.

Palavras-chave: potencial evocado auditivo. audição. valores de normalidade. 